\title{
Difficulties of Breast Reconstruction - Problems That No One Likes to Face
}

\author{
MICHAEL FRIEDRICH $^{1}$, STEFAN KRÄMER ${ }^{1}$, DOMINIQUE FRIEDRICH ${ }^{1}$, \\ CLAYTON KRAFT $^{2}$, NICOLAI MAASS ${ }^{3}$ and CHRISTOPH ROGMANS ${ }^{3}$ \\ ${ }^{1}$ Department of Gynecology and Obstetrics, Helios Klinikum, Krefeld, Germany; \\ ${ }^{2}$ Department of Orthopedics, Trauma Surgery and Hand Unit, Helios Klinikum, Krefeld, Germany; \\ ${ }^{3}$ Department of Gynecology and Obstetrics, Christian-Albrechts-University Kiel \\ and University Medical Center Schleswig-Holstein Campus Kiel, Kiel, Germany
}

\begin{abstract}
Reconstructive breast surgery following total or partial mastectomy can be performed using autologous tissues or breast implants, and each has its own set of complications. Most women do not experience significant complications and are highly satisfied but breast reconstruction must consider potential complications from surgical techniques, as well as additional complications that may arise from oncological treatment modalities such as radiation therapy and chemotherapy. The aim of this article is to provide a systemic overview of possible complications that may arise in the course of reconstructive breast surgery. Complications associated with flap-based or implant-based breast reconstruction can be classified as: i) Complications inherent to surgery and common to all, including seroma, bleeding, and hematoma; skin necrosis; and infection, among others. ii) Complications specifically related to reconstruction, such as flap ischemia/necrosis/loss; fat necrosis; implant capsular contracture; implant failure, exposure, or malposition. In conclusion, this overview of possible complications is intended to improve the decision-making process when considering breast reconstruction.
\end{abstract}

Reconstructive breast surgery has been a key element of surgical therapy for breast carcinoma for decades, with the aim of restoring physical integrity and improving the quality of life of affected

This article is freely accessible online.

Correspondence to: Professor Dr. med. Michael Friedrich, Direktor, Klinik für Frauenheilkunde und Geburtshilfe, Helios Klinikum Krefeld, Lutherplatz 40, 40625 Krefeld, Germany. Tel: +49 2151322201, Fax: +49 2151322220, e-mail: michael.friedrich@helios-gesundheit.de

Key Words: Breast reconstruction, complications, nipple-sparing mastectomy, breast implant, breast cancer, review. patients. From an oncological point of view, the integration of breast reconstruction into multimodal therapy (chemotherapy, radiotherapy) of breast carcinoma is of great importance. Breast reconstruction must consider potential complications from surgical techniques, as well as additional complications that may arise from oncological treatment modalities such as radiation therapy and chemotherapy. Surgical details, further therapy steps and individual patient characteristics can lead to complications, which are systematically reviewed below.

\section{Systematics of Reconstructive Breast Surgery}

In general, three treatment situations can be distinguished in surgical breast reconstruction (Figure 1):

i) Breast-conservation surgery, in which segmental partial defects are reconstructed by local tissue repositioning to avoid contour defects of the breast and to restore the breast shape, size and symmetry to that of the contralateral side. This concept of oncoplastic partial defect reconstruction can also be performed as targeted concept surgery with a few basic surgical techniques that can be learned and taught (targeted oncoplastic breast surgery) (1);

ii) Skin-saving and nipple-saving techniques of mastectomy require immediate reconstruction, usually as implant reconstruction;

iii) Interval reconstruction, in a secondary reconstruction of the breast after mastectomy and tumor therapy to restore the physical integrity and improve the quality of life of patients.

\section{Reconstructive Breast Surgery - Risk of Complications}

Surgical details, individual patient characteristics, and factors specifically related to the treatment of breast cancer increase the risk for some complication. 


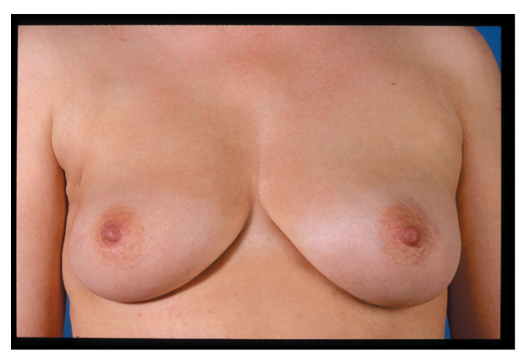

\section{Breast- conserving Therapy}

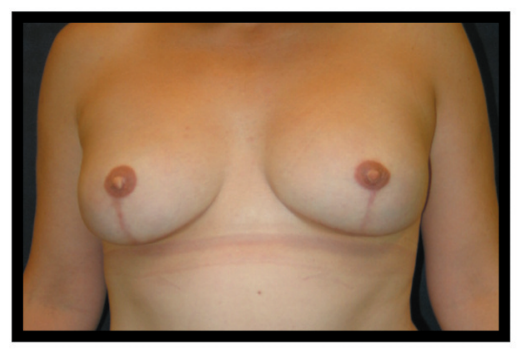

SSM / NSM

\section{Modified \\ radical \\ mastectomy}

\section{Oncoplastic partial defect- reconstruction (TOBS)}

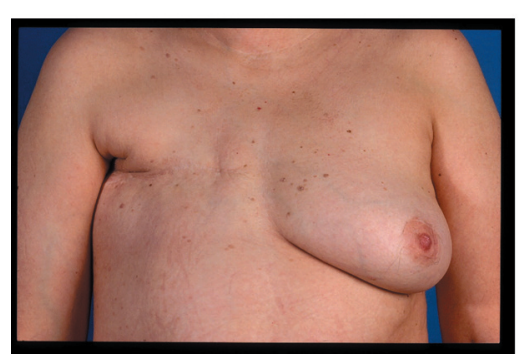

Figure 1. Reconstructive breast surgery: Indications.
Smoking, obesity, and older age are established risk factors (2). Radiotherapy significantly increases the overall risk. Regarding chemotherapy, a meta-analysis showed neither neoadjuvant nor adjuvant chemotherapy affect complication rates after flap- or implant-based breast reconstruction, although wound healing may be delayed (3). Other factors that affect overall complication rates include the type of mastectomy, implant, tissue flap, use of fat grafting, breast size, bilateral surgery, and prior abdominal surgery [for transverse rectus abdominis (TRAM) flap] (4-7).

Patients older than 65 years may have an overall increased risk of perioperative complications compared with younger patients, probably due to medical comorbidities. However, age does not appear to be a predictive factor for reconstructive failure.

The use of acellular matrix (ADMs) is also thought to be associated with an increased risk of complications after implant reconstruction. In a prospective multicenter study, there were no significant differences in major complications, wound infections, or reconstructive failure 2 years after reconstruction when comparing ADM and non-ADM cohorts (8).
Pre-pectoral reconstruction, in which a tissue expander or implant is placed over the pectoralis major muscle, also does not appear to be associated with an increased risk of complications. In a review comparing pre-pectorally placed tissue expander (51 patients, 84 breasts) with subpectoral placement (115 patients, 186 breasts), there was no significant difference in overall complications $(17.9 \%$ versus $18.8 \%$ ) (9). Specific complications included hematoma in $2.4 \%$, seroma in $3.6 \%$, cellulitis in $4.8 \%$, and explantation in $1.2 \%$.

Radiotherapy. Expander or implant reconstruction has a significantly increased complication rate in combination with radiotherapy, regardless of when the radiation therapy is delivered (10). A Mastectomy Reconstruction Outcomes Consortium study compared the outcomes of radiation therapy in the setting of autologous or implant-based breast reconstruction (11). Complications occurred in $25.6 \%$ of 622 irradiated patients after autologous reconstruction and in $38.9 \%$ after implant reconstruction. In 1,625 patients who did not receive radiotherapy, complications occurred in 

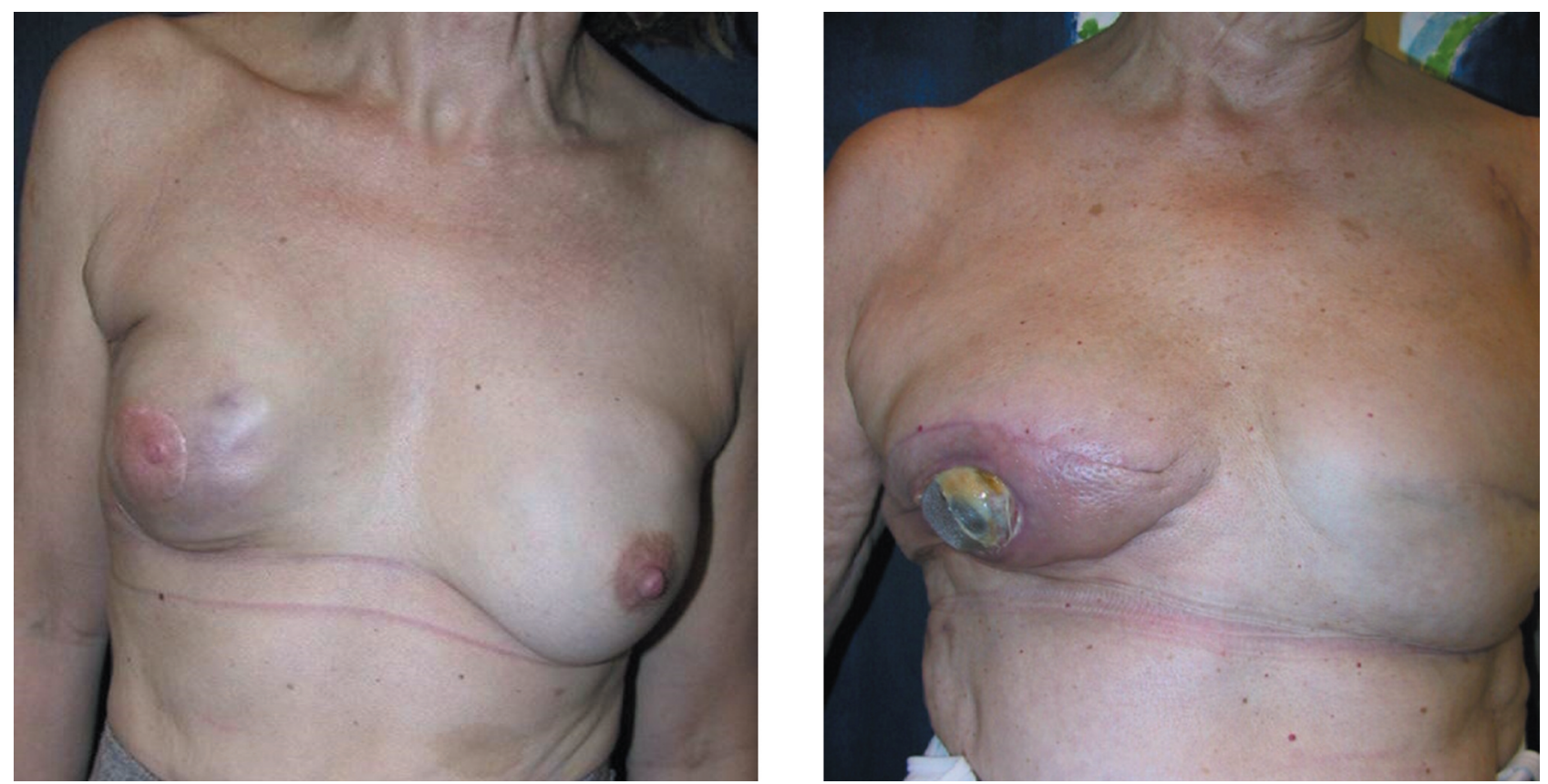

Figure 2. Implant reconstruction following irradiation of the thoracic wall, with capsular fibrosis, dehiscence and skin necrosis.

$28.3 \%$ after autologous reconstruction and in $21.8 \%$ after implant reconstruction.

The consequences of radiation-induced tissue changes include scarring at the implant-tissue junction, capsular contracture, malpositioning, and compromised wound healing, which can lead to dehiscence of the skin incision (Figure 2).

Peled et al. evaluated 218 women after mastectomy and expander/implant reconstruction, of whom 85 patients had undergone prior radiation therapy and 133 underwent postmastectomy radiation therapy (12). Patients with prior radiation therapy had more complications after expander reconstruction than after definitive implant reconstruction, including higher explantation rates $(15 v s .5 \%)$ and infection rates $(20$ vs. 8\%). However, complication rates after definitive implant reconstruction were significantly higher, nearly four-fold, than in patients with prior radiation therapy.

Direct-to-implant reconstruction in the setting of skinsparing mastectomy or nipple-sparing mastectomy may have advantages over two-stage expander/implant reconstruction in the setting of radiation. In a review of 1,286 women, Naoum et al. showed that the cumulative incidence of reconstruction complications after direct-to-implant reconstruction was lower $(18.2 v s .36 .8 \%)$ at a median follow-up of 5.8 years compared with two-stage expander/implant reconstruction (13).

Autologous tissue appears to tolerate radiation-induced tissue damage better than implant-based reconstructions, so the risk of serious complications is not increased. However, flaps may show radiation-induced fat necrosis, fibrosis, atrophy, and flap contracture.

The incidence of late complications (fat necrosis, flap volume loss, flap contracture) is significantly higher in patients with immediate reconstructions that have undergone radiotherapy (14). In a retrospective study of 113 women undergoing radiotherapy after mastectomy and autologous immediate reconstruction, early complications were observed more frequently. Late complications were also more common with autologous immediate reconstruction followed by radiation (32 vs. 44\%) (15). In another study comparing autologous TRAM flap reconstruction before (immediate reconstruction) and after radiation (interval reconstruction), late complications were significantly higher in the immediate reconstruction group compared with the interval reconstruction group (88vs. 9\%) (16).

Smoking. Smoking in general is a risk factor for surgical complications because it affects wound healing and blood supply (17). It is an independent risk factor for the development of perioperative complications and is associated with an increased risk of reconstructive failure. In implantbased reconstruction, the incidence of skin necrosis, infection, and implant loss increases with tobacco use. Smoking cessation before surgical intervention is recommended.

In a study of 155 smokers, 76 ex-smokers, and 517 nonsmokers who underwent autologous breast reconstruction with 
TRAM flaps after mastectomy, the risk of complications was evaluated (18). There were no significant differences in complication rates between nonsmokers and former smokers. Therefore, it is active smoking that is considered to increase the risk of complications for reconstruction with a TRAM flap.

Obesity. Obesity is a challenge for breast reconstruction. Obesity increases the risk of adverse events after autologous or implant-based reconstruction. Several studies showed that obese patients have an increased risk of complications and a poorer cosmetic outcome compared to normal-weight women (19-21). In a review of the National Surgical Quality Improvement Program database, obesity [defined as a body mass index $(\mathrm{BMI})>40 \mathrm{~kg} / \mathrm{m}^{2}$ ] was found to be associated with a significantly increased risk of perioperative complications compared with nonobese patients. This increase in risk was independent of the surgical method chosen (22). In another study of 404 patients, patients with BMI $>40 \mathrm{~kg} / \mathrm{m} 2$ had significantly increased rates of total flap loss $(8.0 \mathrm{vs} .0 .5 \%)$, delayed wound healing at the abdominal wall (72 vs. 44\%), and serious postoperative complications (12 vs. 3\%) (7).

\section{Local Surgical Complications}

Seroma. Seromas can develop with most types of breast reconstruction. Most seromas occur after removal of a drain. Early occurrence of seroma is more common after implant reconstruction than after flap-based breast reconstruction. Seromas can occur at both the donor and recipient sites of autologous tissue reconstruction. Seroma rates of 12 to $21 \%$ have been reported for latissimus dorsi donor sites (23). In a series of deep inferior epigastric perforator (DIEP) flaps, abdominal wall seroma occurred at the donor site in 5\% (24). Seroma at the tissue donor site may require puncture.

Significant fluid accumulation in the breast implant pocket (within the capsule) can lead to asymmetry and breast enlargement (25). Seroma formation increases the risk of implant rotation, malposition, and infection. Seroma formation is increased using reconstruction with an acellular dermal matrix (ADM), and ADM adherence may be impaired if the seroma is not treated (26).

Increased seroma formation may be due to increased implant movement, an oversized pocket, as well as increased patient activity (27)

Early-appearing seromas can be punctured percutaneously. Microbial examination of the wound fluid may be useful if infection is suspected. Once drainage is placed, it usually remains until wound flow is $\leq 30 \mathrm{ml}$ over a 24-hour period.

Late fluid collections around an implant are rare and the etiology is not well understood. These must be assessed according to the patient's clinical situation and include fluid analysis (including cell counts, cytology, and microbiology) and ultrasound or magnetic resonance imaging. Seromas occurring more than 1 year after surgery require cytological evaluation to rule out breast implant-associated anaplastic large-cell lymphoma (ALCL) (28).

Differential diagnoses for late fluid collection in the breast are:

- Hematoma

- Infection with or without biofilm formation

- Implant rupture

- Inflammation

- Double capsule formation

- Malignancy

- Implant-associated ALCL

If infection and malignancy are ruled out, surgical intervention with capsulectomy, implant removal, and drainage may be required if the fluid collection under the drainage device does not regress. Evidence suggests that fluid collection is most common with textured implants and is caused by friction between the rough surfaces of the textured prosthesis and the capsule. In this case, it may be advisable to remove the textured implant and replace it with a smooth implant (29).

Bleeding and hematoma. Hematomas are a rare complication of breast reconstruction overall $(<2 \%)$. The affected breast is enlarged and may show bruising. Hematomas usually develop 12-14 hours after surgery. Rarely, hematomas may occur days or weeks later and are associated with minor injury or trauma to the breast. Data published by Collins et al. showed an incidence of postoperative hematoma of $0.92 \%$ in 3,474 implant procedures (30). Late hematoma is associated with trauma, coagulation disorders, hyperactivity, and the use of intraoperative corticosteroids. Location, incision and implant type are not factors associated with increased hematoma formation. Careful intraoperative hemostasis usually prevents hematoma formation.

Medications associated with an increased bleeding tendency, such as antiplatelet agents, anticoagulants, or androgenic hormones, should be stopped preoperatively.

Treatment of a hematoma includes its evacuation and hemostasis. Capsular contracture is a common consequence of hematoma formation (31).

Skin necrosis. Skin necrosis is a complication that should be explained in detail prior to surgery. The increased use of nipple-sparing mastectomy in immediate reconstruction has led to an increasing incidence (32).

Several studies showed an association of skin necrosis and nipple-sparing mastectomy $(32,33)$. This can be attributed to hypoperfusion of the nipple-areolar complex. Depending on the study, the incidence was found to range from 0 to $48 \%$ (34). Increased BMI, tobacco use, and prior breast irradiation increase the risk of skin flap necrosis $(17,21)$. Komorowska-Timek et al. showed that the use of indocyanine green perfusion significantly reduced the 


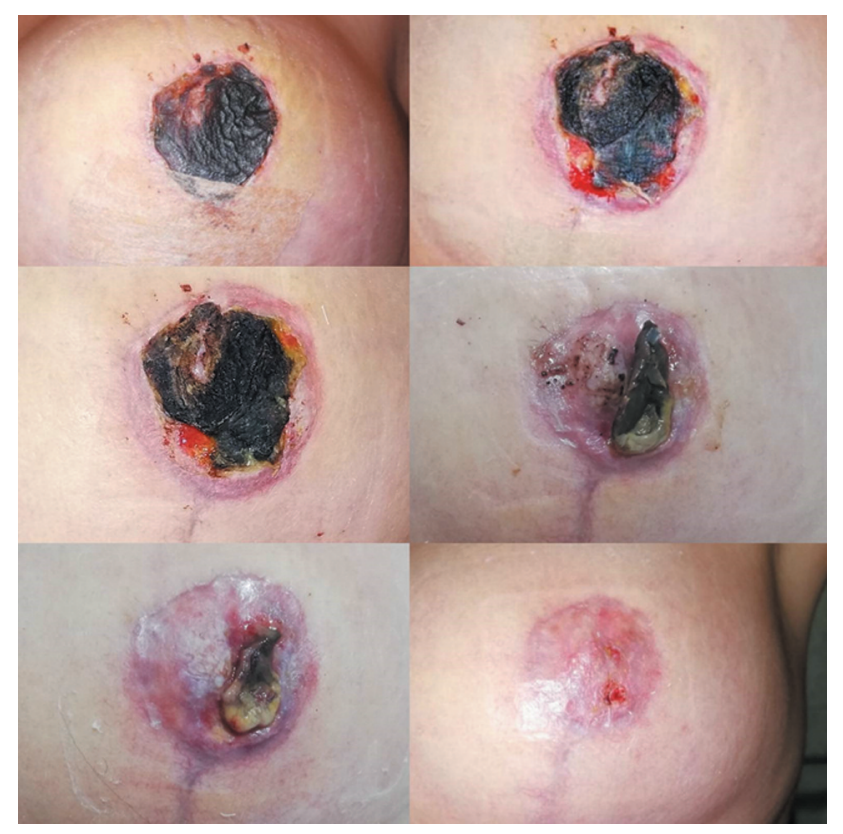

Figure 3. Nipple necrosis with conservative treatment after nipplesparing mastectomy and implant reconstruction.

incidence of overall complications and reduced the risk of skin flap necrosis during mastectomy from 15.1 to $4 \%$ (35).

To reduce skin flap necrosis during mastectomy, preservation of the subdermal plexus, atraumatic skin treatment during mastectomy, and minimization of thermal damage are essential. If swelling, discoloration, or signs of ischemia occur postoperatively, removing volume added to the expander or avoiding pressure with external bandages may be appropriate.

If the area of necrosis is small and closure is possible without excessive tension, debridement with primary closure should be performed. If the skin flap loss is larger, a more conservative approach can be taken if the expander is protected by muscle coverage or $\mathrm{ADM}$ and there is no evidence of infection (Figure 3).

Flap complications. For autologous tissue reconstruction of the breast, pedicled flaps and free perforator flaps can be used. Depending on the donor site and surgical technique, different complications may occur. The main complications of autologous tissue reconstruction are flap and fat tissue necrosis, hernia, and lower abdominal flaccidity.

The use of latissimus dorsi flap reconstruction, which is usually performed in combination with expander/implant reconstruction to achieve a necessary reconstruction volume, has declined significantly in recent years (36). The reason for this in the case of whole-breast reconstruction is, among other things, the limitation of shoulder-arm morbidity.
Individual anatomy, as well as experience with autologous reconstruction procedures, have a significant impact on complication rates of the procedure, which may include complete flap loss because of necrosis.

A retrospective analysis of the National Surgical Quality Improvement Program database of 3,296 patients who underwent autologous breast reconstruction found that complication rates with free perforator flaps, compared with pedicled TRAM flap and latissimus dorsi flaps, were significantly higher (19.4 vs. 13.4 vs. 7.1\%) (37). In autologous reconstruction with free perforator flap, the reoperation rate (15.6 vs. 9.9 vs. $5.7 \%$ ) and flap failure (5.7vs. 3.4 vs. 3\%) were higher compared with pedicled reconstructions. However, the differences were not significant. Overall, flap failure and reoperation rates are less than $2 \%$ and $5 \%$, respectively, when reconstructions are performed by experienced operators.

The data of Gill et al. demonstrate the incidence of partial flap necrosis to be $2.5 \%$ and complete flap necrosis $0.5 \%$; $5.9 \%$ of patients required reoperation. The main cause was venous congestion (24).

Flap necrosis/loss. Flap failure is a rare complication in breast reconstruction and occurs when the blood supply to the flap is not guaranteed. This can occur due to both arterial and venous occlusion. Overall, pedicled flaps, such as the latissimus dorsi and TRAM flaps, in which the blood supply is not reconnected, are associated with lower rates of necrosis $(<1 \%)$ than free flaps, such as the DIEP flap (2 to $5 \%$ ).

When total flap loss occurs $(\leq 1 \%)$, surgery must be performed to remove the necrotic tissue and reconstruct the breast. Partial flap loss limited to small areas of skin can usually be treated conservatively. Inferior perfusion of the fat region of the flap can lead to fat necrosis and loss of the flap. The consecutive tissue fibrosis and calcification may feel like a tumor on postoperative physical examination.

Some studies show that fat necrosis is more common in DIEP flaps compared with TRAM flaps. In their study, Chun et al. examined 105 women with bilateral pedicled TRAM flaps and 58 women with bilateral DIEP flap reconstructions. The DIEP flap cohort had significantly higher rates of partial skin loss, wound dehiscence, and fat necrosis (5). Gill et al. described flap problems in approximately $6 \%$ of patients who required surgery (24). Partial flap loss occurred in $2.5 \%$ and complete flap loss in fewer than $1 \%$ of cases; $13 \%$ of patients showed fat necrosis (risk factors were smoking and radiotherapy after reconstruction).

Complications associated with donor tissue. Obesity, active smoking, collagen vascular disease, diabetes, radiation therapy after mastectomy, and the presence of certain abdominal scars increase the risk of wound healing problems at the donor site. Nelsen et al. studied abdominal wall functionality and strength after autologous breast reconstruction with free abdominal 
flaps (DIEP, TRAM, and SIEA flaps). Fifty-one patients were included with a mean follow-up of 8.1 years (38). Reconstruction with free flaps was associated with improved long-term quality of life in terms of physical and mental health. It showed only minor functional impairment related to the choice of surgical procedure.

Hernia. Hernias are defined as fascial defects. These may occur after autologous reconstruction from the abdominal wall and are related to the degree of injury the procedure. Chun et al. demonstrated that the rate of abdominal wall herniation was similar using bilateral pedicled TRAM flaps and bilateral DIEP flaps (5). The incidence of hernia in reconstructions using DIEP flaps was $0.7 \%$ (24).

Minor abdominal wall weaknesses are often asymptomatic. Prominent hernias often require surgical repair in form of duplication of the anterior rectus sheath or reinforcement with mesh. A mesh-free three-layer closure of the fascial defect is recommended for a unilaterally pedicled TRAM (Figure 4).

\section{Implant-based Complications}

Capsular contracture and implant failure are common complications of breast reconstruction with implants and expanders (e.g., rupture, deflation, malposition).

Capsular contracture. Capsular contracture is a common risk in breast implant reconstruction. A thin capsule of connective tissue forms around the breast implant and does not usually cause symptoms. If the capsule is thickened or calcified, it can cause breast pain, hypersensitivity, and distortion (39). Most capsular contractures occur within 12 months after surgery. The use of an ADM in implant reconstructions may reduce the incidence of capsular contracture.

Vardanian et al. compared 123 patients with ADM and 80 without ADM reconstruction. The capsular contracture rate with ADM was 3.8\% and without ADM was 19.4\% (40). Several factors can contribute to the development of capsular contracture. These include size of the implant, the patient's scarring tendency, and circulating bacteria.

Although poorly studied, capsular contracture is assumed to be due to low-grade subclinical bacterial infection and the formation of a bacterial biofilm (39). Chronic inflammatory process may also be a possible reason for capsular contracture (39). Capsular contractures occur much less frequently in nonsmokers $(8 \%$ in smokers vs. $3 \%$ in nonsmokers) (41). Hematomas can also lead to capsular contractures (30).

Performing radiation may increase the risk of capsular contracture in breast reconstruction (compared to augmentation). Jagsi et al. showed that capsular contracture developed in only $3 \%$ of female patients but it occurred in four out of five cases of previously irradiated patients (11).
Regarding the influence of chemotherapy on capsular contracture, no definitive results are available. By using implants with a textured surface instead of a smooth surface, capsular contracture rates might be reduced.

Lower rates of capsular contracture are associated with partial or complete submuscular or subfascial implant placement. In a multicenter study of more than 500 patients, subglandular (compared with submuscular) implant placement resulted in an almost eight-fold increase in the risk of capsular contracture (42).

Nevertheless, the epipectoral plane of implantation is being used with increasing frequency (43). This preserves the integrity of the pectoralis major muscle and eliminates the need for additional mesh materials and acellular matrix in the caudal pole of the breast. There is no distortion during contraction of the pectoralis major muscle ('jumping breast') (44). The foreign body sensation is also less pronounced. In the case of significant capsular fibrosis with the need for surgical revision, we recommend conversion to autologous reconstruction (DIEP).

Classification of capsular fibrosis. The Baker classification (45) is used for assessing the severity of breast implant capsules:

- Baker I: The breast is soft with no palpable capsule and looks natural.

- Baker II: The breast is slightly firmer with a palpable capsule, but looks normal.

- Baker III: Breast is firm with a slightly palpable capsule and does not look visually normal.

- Baker IV: The breast is hard, cold, painful, and markedly distorted.

Baker contractures of grades III and IV are generally classified as complications. Baker grades I and II are generally not included in complication rates and treatment recommendations.

Treatment of capsular fibrosis. A surgical approach should be taken for Baker III and IV capsules (capsulotomy, capsulectomy, implant exchange).

Open capsulotomy involves internal circumferential and longitudinal incisions through the capsule. This leaves the capsule in place on the tissue but results in widening of the implant pocket and improves implant deformation. During capsulectomy, the affected scar tissue and capsule are removed. Although open capsulotomy may improve symptoms in the short term, the recurrence rate is high (46).

In the case of significant adhesions to the thoracic wall, a partial (or anterior) capsulectomy can be performed. After capsulectomy, an ADM can be placed to create a dual plane pocket (46). This places the upper two-thirds of the implant below the pectoralis major muscle and the lower third in an epipectoral position. One reason why ADMs reduce the risk 

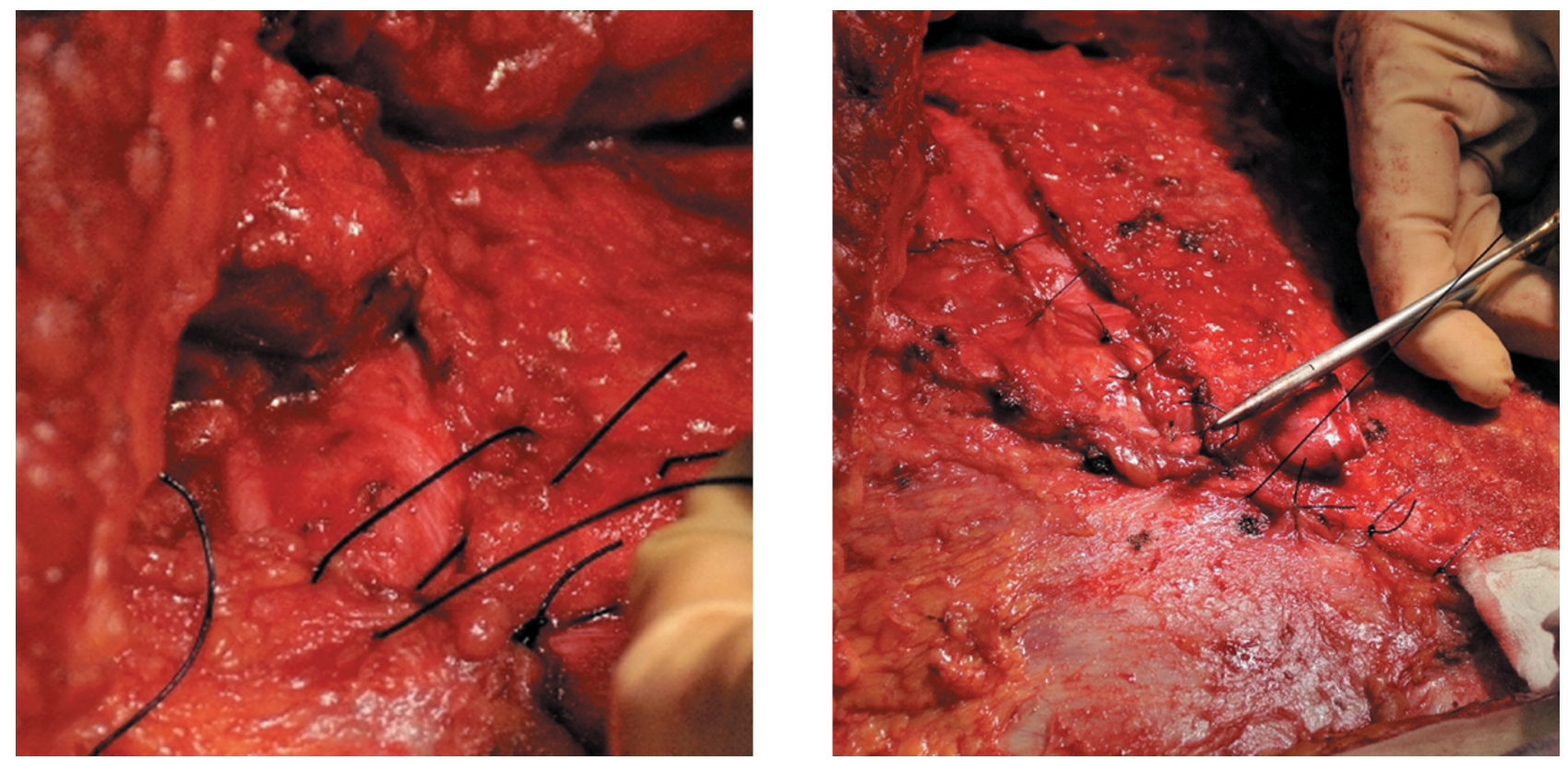

Figure 4. Prophylaxis of hernias by meshfree closure of donor defect after transverse rectus abdominis flap (three layers).
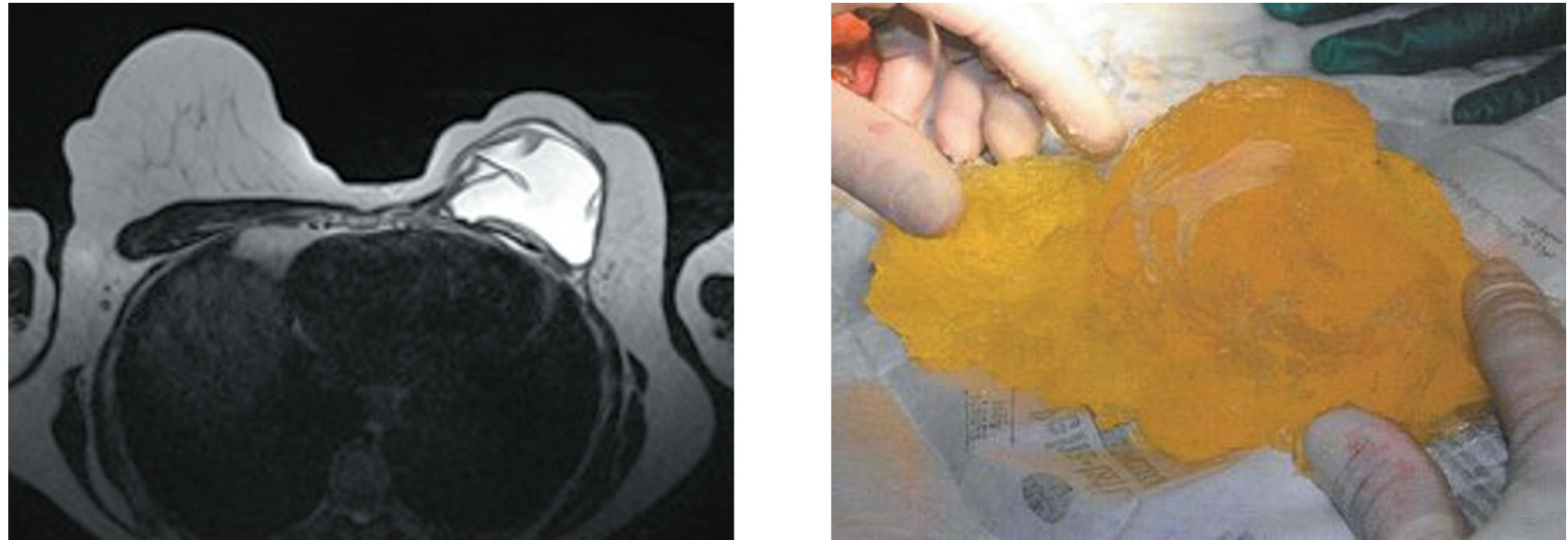

Figure 5. Intracapsular rupture of the implant - magnetic resonance imaging (left) and intraoperative view (right).

of capsular contracture may be the reduced level of bacterial colonization (47).

When there is a pronounced capsular contracture that cannot be successfully treated despite all possible treatments [i.e. capsulectomy with implant reconstruction or rearrangement of the implantation plane from epipectoral to subpectoral (dual plane) with mesh or ADM], patients should be offered capsulectomy with implant removal and autologous tissue replacement (48).
Implant rupture. Intracapsular ruptures are also called silent ruptures. These are often not detected until a routine mammogram or ultrasound (Figure 5). Extracapsular ruptures can trigger local inflammation and cause granuloma formation such as siliconomas (49).

The US Food and Drug Administration recommendation is that women with silicone gel breast implants should undergo mammographic imaging 3 years after surgery and every 2 years thereafter. Magnetic resonance imaging is the 
most sensitive and specific imaging modality. Overall, the utility of these examinations is questionable because implant ruptures are rare in the first 3 to 5 years after implant placement (50).

When an implant has ruptured it should be removed. Otherwise, inflammation and other tissue reactions may be favored. In this case, a capsulectomy is usually performed to remove the gel material from the breast pocket, especially because there is a possibility of the development of ALCL in women with ruptured textured implants.

Nevertheless, there is no clear evidence that developing silicone granuloma contributes to systemic disease (49).

Breast implant-associated ALCL. This can occur in the scar capsule next to a breast implant filled with silicone or saline. Overall, its incidence in women with breast implants is extremely low. The median time from implantation to breast implant-associated ALCL diagnosis is reported to be 10,3 years $(51)$.

The leading symptom of breast implant-associated ALCL was reported as periprosthetic fluid collection in $86 \%$ of patients. In addition, almost all patients had implants with textured surfaces. As of July 2019, 573 individual cases with 33 deaths have been confirmed worldwide (52). Of these cases, 481 were attributed to implants from the manufacturer Allergan. Allergan was also the manufacturer in 12 out of 13 deaths in which the specific manufacturer of the implant was known. No cases of ALCL have been reported in patients with smooth implants. For this reason, the Food and Drug Administration required Allergan to remove all textured implants from the market in July 2019.

Wrinkling and palpability. A common esthetic problem is wrinkling of the implant. This causes skin irregularities that are typically visible at the lateral edge of the breast. This problem is more common in slender patients and with subglandular placement of saline implants. Textured implants are more likely to experience wrinkling and rippling and may be less suitable for patients with thin skin soft-tissue mantles.

In patients with a BMI of less than $18.5 \mathrm{~kg} / \mathrm{m}^{2}$, submuscular placement or the use of a silicone implant may be beneficial to minimize the risk of rippling. Saline implants may have the advantage of being less palpable in very slender patients, especially at the lateral and lower edges of the breast. Rippling can also be reduced by placing an ADM in the appropriate area of the breast pocket or by injecting autologous fat grafts (lipofilling).

Breast asymmetry. Asymmetry is related to both the patient's expectation and the surgeon's experience. The better the challenges are explained to the patient upfront, the higher the acceptance of the result. When immediate reconstruction is performed, complete adaptation and symmetry of the breasts is often expected by the first postoperative day. Usually, the shape of the adapted breast differs compared to the nonoperated breast. Some asymmetries in terms of volume, shape and position of the nipple-areolar complex are also found in almost every non-operated woman. To assess asymmetry, one considers the following aspects: The position of the nippleareola complex, height of the inframammary fold, and the size and shape of the reconstructed breast compared to the contralateral breast. Meaningful assessment of asymmetry can be performed only from about 3 months after surgery. Photographic documentation to note asymmetries during the initial examination may be useful. This can be helpful for patients to better manage potential changes after reconstruction. Many breast reconstruction patients have a recurring desire for absolute symmetry of both breasts.

Inframammary fold asymmetry can be avoided by correct implant placement. The use of ADM can help to fix the fold at a precise level (e.g., Rhyan's surgery). Secondary procedures on the contralateral breast may often be required (53). Adjustments in areola position and various mastopexy techniques can resolve asymmetries compared with the opposite side. Postoperative breast asymmetry is more common after unilateral reconstruction than after bilateral procedures, especially after nipple-sparing mastectomy.

\section{Summary}

- Reconstructive breast surgery following total or partial mastectomy can be performed using autologous tissues or breast implants, and each has its own set of complications.

- Most women do not experience significant complications and are highly satisfied; however, a range of problems can occur any time following reconstructive breast surgery, which are important to consider for women pursuing these options.

- Complications associated with flap-based or implant-based breast reconstruction that may or may not lead to reoperation can be classified as those:

- inherent to surgery and common to all, including seroma, bleeding, and hematoma; skin necrosis; and infection, among others.

- specifically related to the reconstruction, such as flap ischemia/necrosis/loss; fat necrosis; implant capsular contracture; implant failure, exposure, or malposition.

- Failure of silicone gel implants is difficult to detect since the gel typically remains confined within the breast capsule (intracapsular rupture) but in some cases it may extrude into the breast tissue and beyond (extracapsular rupture). Ruptured silicone gel implants should be removed due to the possibility of the gel material causing inflammation and other tissue reactions, particularly when rupture is extracapsular. 
- ALCL has been associated with breast implants, located within the scar capsule adjacent to a silicone or saline-filled breast implant. Prophylactic breast implant removal in patients without symptoms or other abnormalities is not recommended.

\section{Conclusion}

Reconstructive breast surgery has been a key element of surgical therapy for breast carcinoma for decades. Comprehensive education about potential complications prior to reconstructive surgery is critical. Complications depend on individual patient characteristics, type of mastectomy, multimodality breast cancer therapies (chemotherapy, radiation therapy), and choice of reconstruction method (alloplastic or autologous). Due to the complexity of reconstructive breast surgery, its success is largely dependent on the experience of the surgeon.

A solid training in senology includes reconstructive breast surgery and should continue to enable specialized gynecologic breast surgeons at certified breast centers to recognize, avoid and treat complications. Knowledge of possible pitfalls is essential for the lasting success of breast reconstruction.

\section{Conflicts of Interest}

The Authors declare no conflicts of interest.

\section{Authors' Contributions}

M.F. and S.K. developed the project idea and supervised the work; S.K. and C.R. wrote and prepared the original draft; N.M. and D.F. reviewed and edited the article. C.K. checked the English spelling as a native speaker. All Authors have read and agreed to the published version of the article.

\section{References}

1 Kraemer S, Rezai M, Malter W and Friedrich M: Local breast cancer treatment with targeted oncoplastic breast surgery. Clinical Obstetrics, Gynecology and Reproductive Medicine 4(4), 2018. DOI: 10.15761/COGRM.1000226

2 Voineskos SH, Frank SG and Cordeiro PG: Breast reconstruction following conservative mastectomies: predictors of complications and outcomes. Gland Surg 4(6): 484-496, 2015. PMID: 26645003. DOI: 10.3978/j.issn.2227-684X.2015.04.13

3 Song J, Zhang X, Liu Q, Peng J, Liang X, Shen Y, Liu H and Li $\mathrm{H}$ : Impact of neoadjuvant chemotherapy on immediate breast reconstruction: a meta-analysis. PLoS One 9(5): e98225, 2014. PMID: 24878776. DOI: 10.1371/journal.pone.0098225

4 Chattha A, Bucknor A, Kamali P, Van Veldhuisen CL, FlechaHirsch R, Sharma R, Tobias AM, Lee BT and Lin SJ: Comparison of risk factors and complications in patients by stratified mastectomy weight: An institutional review of 1041 consecutive cases. J Surg Oncol 116(7): 811-818, 2017. PMID: 28833196. DOI: $10.1002 /$ jso .24753
5 Chun YS, Sinha I, Turko A, Yueh JH, Lipsitz S, Pribaz JJ and Lee BT: Comparison of morbidity, functional outcome, and satisfaction following bilateral TRAM versus bilateral DIEP flap breast reconstruction. Plast Reconstr Surg 126(4): 1133-1141, 2010. PMID: 20555301. DOI: 10.1097/PRS.0b013e3181ea42d3

6 Woo KJ, Paik JM, Mun GH, Pyon JK and Bang SI: Risk factors for complications in immediate expander-implant breast reconstruction for non-obese patients: impact of breast size on complications. Aesthetic Plast Surg 40(1): 71-78, 2016. PMID: 26530484. DOI: $10.1007 / \mathrm{s} 00266-015-0568-7$

7 Jandali S, Nelson JA, Sonnad SS, Low DW, Kovach SJ, Wu LC and Serletti JM: Breast reconstruction with free tissue transfer from the abdomen in the morbidly obese. Plast Reconstr Surg 127(6): 2206-2213, 2011. PMID: 21617454. DOI: 10.1097/ PRS.0b013e3182131c93

8 Sorkin M, Qi J, Kim HM, Hamill JB, Kozlow JH, Pusic AL and Wilkins EG: Acellular dermal matrix in immediate expander/implant breast reconstruction: a multicenter assessment of risks and benefits. Plast Reconstr Surg 140(6): 1091-1100, 2017. PMID: 28806288. DOI: 10.1097/PRS.0000000000003842

9 Sbitany H, Piper $M$ and Lentz R: Prepectoral breast reconstruction: A safe alternative to submuscular prosthetic reconstruction following nipple-sparing mastectomy. Plast Reconstr Surg 140(3): 432-443, 2017. PMID: 28574950. DOI: 10.1097/PRS.0000000000003627

10 Momoh AO, Ahmed R, Kelley BP, Aliu O, Kidwell KM, Kozlow $\mathrm{JH}$ and Chung KC: A systematic review of complications of implant-based breast reconstruction with prereconstruction and postreconstruction radiotherapy. Ann Surg Oncol 21(1): 118-124, 2014. PMID: 24081801. DOI: 10.1245/s10434-013-3284-z

11 Jagsi R, Momoh AO, Qi J, Hamill JB, Billig J, Kim HM, Pusic $\mathrm{AL}$ and Wilkins EG: Impact of radiotherapy on complications and patient-reported outcomes after breast reconstruction. J Natl Cancer Inst 110(2): 157-165, 2018. PMID: 28954300. DOI: 10.1093/jnci/djx 148

12 Peled AW, Sears M, Wang F, Foster RD, Alvarado M, Wong J, Ewing CA, Sbitany H, Esserman LJ and Fowble B: Complications after total skin-sparing mastectomy and expanderimplant reconstruction: Effects of radiation therapy on the stages of reconstruction. Ann Plast Surg 80(1): 10-13, 2018. PMID: 28671888. DOI: $10.1097 /$ SAP.0000000000001186

13 Naoum GE, Salama L, Niemierko A, Vieira BL, Belkacemi Y, Colwell AS, Winograd J, Smith B, Ho A and Taghian AG: Single stage direct-to-implant breast reconstruction has lower complication rates than tissue expander and implant and comparable rates to autologous reconstruction in patients receiving postmastectomy radiation. Int J Radiat Oncol Biol Phys 106(3): 514-524, 2020. PMID: 31756414. DOI: 10.1016/j.jjrobp.2019.11.008

14 Kelley BP, Ahmed R, Kidwell KM, Kozlow JH, Chung KC and Momoh AO: A systematic review of morbidity associated with autologous breast reconstruction before and after exposure to radiotherapy: are current practices ideal? Ann Surg Oncol 21(5): 1732-1738, 2014. PMID: 24473643. DOI: 10.1245/s10434-0143494-z

15 Adesiyun TA, Lee BT, Yueh JH, Chen C, Colakoglu S, Anderson KE, Nguyen MD and Recht A: Impact of sequencing of postmastectomy radiotherapy and breast reconstruction on timing and rate of complications and patient satisfaction. Int $\mathbf{J}$ Radiat Oncol Biol Phys 80(2): 392-397, 2011. PMID: 20584583. DOI: $10.1016 /$ j.ijrobp.2010.02.039 
16 Schechter NR, Strom EA, Perkins GH, Arzu I, McNeese MD, Langstein HN, Kronowitz SJ, Meric-Bernstam F, Babiera G, Hunt KK, Hortobagyi GN and Buchholz TA: Immediate breast reconstruction can impact postmastectomy irradiation. Am J Clin Oncol 28(5): 485-494, 2005. PMID: 16199989. DOI: 10.1097/ 01.coc.0000170582.38634.b6

17 Coon D, Tuffaha S, Christensen J and Bonawitz SC: Plastic surgery and smoking: a prospective analysis of incidence, compliance, and complications. Plast Reconstr Surg 131(2): 385-391, 2013. PMID: 23358000. DOI: 10.1097/PRS.0b013e318277886a

18 Padubidri AN, Yetman R, Browne E, Lucas A, Papay F, Larive $\mathrm{B}$ and Zins J: Complications of postmastectomy breast reconstructions in smokers, ex-smokers, and nonsmokers. Plast Reconstr Surg 107(2): 342-9; discussion 350-1, 2001. PMID: 11214048. DOI: 10.1097/00006534-200102000-00007

19 Chang DW, Wang B, Robb GL, Reece GP, Miller MJ, Evans GR, Langstein HN and Kroll SS: Effect of obesity on flap and donorsite complications in free transverse rectus abdominis myocutaneous flap breast reconstruction. Plast Reconstr Surg 105(5): 1640-1648, 2000. PMID: 10809092. DOI: 10.1097/0000 6534-200004050-00007

20 Atisha DM, Alderman AK, Kuhn LE and Wilkins EG: The impact of obesity on patient satisfaction with breast reconstruction. Plast Reconstr Surg 121(6): 1893-1899, 2008. PMID: 18520874. DOI: 10.1097/PRS.0b013e3181715198

21 Palve J, Luukkaala T and Kääriäinen M: Is there any difference in perioperative characteristics or postoperative complications between overweight, normal-weight and obese patients in delayed DIEP reconstructions? J Plast Surg Hand Surg: 1-6, 2021. PMID: 34370604. DOI: 10.1080/2000656X.2021.1962334

22 Fischer JP, Cleveland EC, Nelson JA, Kovach SJ, Serletti JM, Wu LC and Kanchwala S: Breast reconstruction in the morbidly obese patient: assessment of 30-day complications using the 2005 to 2010 National Surgical Quality Improvement Program data sets. Plast Reconstr Surg 132(4): 750-761, 2013. PMID: 24076667. DOI: 10.1097/PRS.0b013e31829fe33c

23 Tomita K, Yano K, Masuoka T, Matsuda K, Takada A and Hosokawa K: Postoperative seroma formation in breast reconstruction with latissimus dorsi flaps: a retrospective study of 174 consecutive cases. Ann Plast Surg 59(2): 149-151, 2007. PMID: 17667407. DOI: 10.1097/SAP.0b013e31802c54ef

24 Gill PS, Hunt JP, Guerra AB, Dellacroce FJ, Sullivan SK, Boraski J, Metzinger SE, Dupin CL and Allen RJ: A 10-year retrospective review of 758 DIEP flaps for breast reconstruction. Plast Reconstr Surg 113(4): 1153-1160, 2004. PMID: 15083015. DOI: $10.1097 / 01$.prs.0000110328.47206.50

25 Sbitany H and Serletti JM: Acellular dermis-assisted prosthetic breast reconstruction: a systematic and critical review of efficacy and associated morbidity. Plast Reconstr Surg 128(6): 1162-1169, 2011. PMID: 22094735. DOI: 10.1097/PRS.0b013e318230c29e

26 Michelotti BF, Brooke S, Mesa J, Wilson MZ, Moyer K, Mackay DR, Neves RI and Potochny J: Analysis of clinically significant seroma formation in breast reconstruction using acellular dermal grafts. Ann Plast Surg 71(3): 274-277, 2013. PMID: 23788150. DOI: $10.1097 /$ SAP.0b013e3182923dc9

27 Pinchuk V and Tymofii O: Seroma as a late complication after breast augmentation. Aesthetic Plast Surg 35(3): 303-314, 2011. PMID: 20953952. DOI: 10.1007/s00266-010-9607-6

28 Kim B, Roth C, Chung KC, Young VL, van Busum K, Schnyer C and Mattke S: Anaplastic large cell lymphoma and breast implants: a systematic review. Plast Reconstr Surg 127(6): 2141-2150, 2011. PMID: 21358562. DOI: 10.1097/PRS.0b013e3182172418

29 Hall-Findlay EJ: Discussion: Managing late periprosthetic fluid collections (seroma) in patients with breast implants: a consensus panel recommendation and review of the literature. Plast Reconstr Surg 128(1): 10-12, 2011. PMID: 21701293. DOI: $10.1097 /$ PRS.0b013e318219c050

30 Collins JB and Verheyden CN: Incidence of breast hematoma after placement of breast prostheses. Plast Reconstr Surg 129(3): 413e-420e, 2012. PMID: 22373988. DOI: 10.1097/PRS. 0b013e3182402ce 0

31 Handel N, Cordray T, Gutierrez J and Jensen JA: A long-term study of outcomes, complications, and patient satisfaction with breast implants. Plast Reconstr Surg 117(3): 757-67; discussion 768-72, 2006. PMID: 16525261. DOI: 10.1097/01.prs.0000201457.00772.1d

32 Daar DA, Abdou SA, Rosario L, Rifkin WJ, Santos PJ, Wirth GA and Lane KT: Is there a preferred incision location for nipple-sparing mastectomy? A systematic review and metaanalysis. Plast Reconstr Surg 143(5): 906e-919e, 2019. PMID: 30789474. DOI: 10.1097/PRS.0000000000005502

33 Pestana IA, Jones VM and Velazquez C: Breast reconstruction and nipple-sparing mastectomy: Technical modifications and their outcomes over time at an academic Breast center. Ann Plast Surg 86(6S Suppl 5): S521-S525, 2021. PMID: 34100809. DOI: 10.1097/SAP.0000000000002701

34 Rusby JE, Smith BL and Gui GP: Nipple-sparing mastectomy. Br J Surg 97(3): 305-316, 2010. PMID: 20101646. DOI: 10.1002/bjs.6970

35 Komorowska-Timek E and Gurtner GC: Intraoperative perfusion mapping with laser-assisted indocyanine green imaging can predict and prevent complications in immediate breast reconstruction. Plast Reconstr Surg 125(4): 1065-1073, 2010. PMID: 20335859. DOI: 10.1097/PRS.0b013e3181d17f80

36 Panchal $\mathrm{H}$ and Matros E: Current trends in postmastectomy breast reconstruction. Plast Reconstr Surg 140(5S Advances in Breast Reconstruction): 7S-13S, 2017. PMID: 29064917. DOI: 10.1097/PRS.0000000000003941

37 Gart MS, Smetona JT, Hanwright PJ, Fine NA, Bethke KP, Khan SA, Wang $\mathrm{E}$ and Kim JY: Autologous options for postmastectomy breast reconstruction: a comparison of outcomes based on the American College of Surgeons National Surgical Quality Improvement Program. J Am Coll Surg 216(2): 229-238, 2013. PMID: 23211118. DOI: 10.1016/j.jamcollsurg.2012.11.003

38 Nelson JA, Tecci MG, Lanni MA, Fischer JP, Fosnot J, Selber JC, Wu LC and Serletti JM: Function and strength after free abdominally based breast reconstruction: A 10-year follow-up. Plast Reconstr Surg 143(1): 22e-31e, 2019. PMID: 30431541. DOI: $10.1097 /$ PRS.0000000000005096

39 Araco A, Caruso R, Araco F, Overton J and Gravante G: Capsular contractures: a systematic review. Plast Reconstr Surg 124(6): 1808-1819, 2009. PMID: 19952637. DOI: 10.1097/PRS. 0b013e3181bf7f 26

40 Vardanian AJ, Clayton JL, Roostaeian J, Shirvanian V, Da Lio A, Lipa JE, Crisera C and Festekjian JH: Comparison of implant-based immediate breast reconstruction with and without acellular dermal matrix. Plast Reconstr Surg 128(5): 403e-410e, 2011. PMID: 22030500. DOI: 10.1097/PRS.0b013e31822b6637

41 Marques M, Brown SA, Oliveira I, Cordeiro MNDS, MoralesHelguera A, Rodrigues A and Amarante J: Long-term follow-up of breast capsule contracture rates in cosmetic and reconstructive 
cases. Plast Reconstr Surg 126(3): 769-778, 2010. PMID: 20463624. DOI: 10.1097/PRS.0b013e3181e5f7bf

42 Gutowski KA, Mesna GT and Cunningham BL: Saline-filled breast implants: a Plastic Surgery Educational Foundation multicenter outcomes study. Plast Reconstr Surg 100(4): 10191027, 1997. PMID: 9290673. DOI: 10.1097/00006534-1997090 01-00028

43 Plachinski SJ, Boehm LM, Adamson KA, LoGiudice JA and Doren EL: Comparative analysis of prepectoral versus subpectoral implant-based breast reconstruction. Plast Reconstr Surg Glob Open 9(7): e3709, 2021. PMID: 34422525. DOI: 10.1097/GOX.0000000000003709

44 Spear SL, Schwartz J, Dayan JH and Clemens MW: Outcome assessment of breast distortion following submuscular breast augmentation. Aesthetic Plast Surg 33(1): 44-48, 2009. PMID: 19052809. DOI: 10.1007/s00266-008-9275-y

45 Spear SL and Baker JL Jr: Classification of capsular contracture after prosthetic breast reconstruction. Plast Reconstr Surg 96(5): 1119-23; discussion 1124, 1995. PMID: 7568488.

46 Hester TR Jr, Ghazi BH, Moyer HR, Nahai FR, Wilton M and Stokes L: Use of dermal matrix to prevent capsular contracture in aesthetic breast surgery. Plast Reconstr Surg 130(5 Suppl 2): 126S-136S, 2012. PMID: 23096962. DOI: 10.1097/PRS.0b $013 \mathrm{e} 3182605 \mathrm{~d} 18$

47 Spear SL, Seruya M, Clemens MW, Teitelbaum S and Nahabedian MY: Acellular dermal matrix for the treatment and prevention of implant-associated breast deformities. Plast Reconstr Surg 127(3): 1047-1058, 2011. PMID: 21088648. DOI: 10.1097/PRS.0b013e31820436af

48 Spear SL, Carter ME and Ganz JC: The correction of capsular contracture by conversion to "dual-plane" positioning: technique and outcomes. Plast Reconstr Surg 112(2): 456-466, 2003. PMID: 12900603. DOI: 10.1097/01.PRS.0000070987.15303.1A
49 Hölmich LR, Lipworth L, McLaughlin JK and Friis S: Breast implant rupture and connective tissue disease: a review of the literature. Plast Reconstr Surg 120(7 Suppl 1): 62S-69S, 2007. PMID: 18090815. DOI: 10.1097/01.prs.0000286664.50274.f2

50 Cher DJ, Conwell JA and Mandel JS: MRI for detecting silicone breast implant rupture: meta-analysis and implications. Ann Plast Surg 47(4): 367-380, 2001. PMID: 11601570. DOI: 10.1097/ 00000637-200110000-00002

51 Nelson JA, Dabic S, Mehrara BJ, Cordeiro PG, Disa JJ, Pusic AL, Matros E, Dayan JH, Allen RJ Jr, Coriddi M, Polanco TO, Shamsunder MG, Wiser I, Morrow M, Dogan A, Cavalli MR, Encarnacion E, Lee ME and McCarthy CM: Breast implantassociated anaplastic large cell lymphoma incidence: determining an accurate risk. Ann Surg 272(3): 403-409, 2020. PMID: 32694446. DOI: 10.1097/SLA.0000000000004179

52 FDA takes action to protect patients from risk of certain textured breast implants; requests Allergan voluntarily recall certain breast implants and tissue expanders from market I FDA. Available at: https://www.fda.gov/news-events/press-announcements/fda-takesaction-protect-patients-risk-certain-textured-breast-implantsrequests-allergan [Last accessed on September 27, 2021]

53 Nahabedian MY: Symmetrical breast reconstruction: analysis of secondary procedures after reconstruction with implants and autologous tissue. Plast Reconstr Surg 115(1): 257-260, 2005. PMID: 15622260. 